\title{
Tristetraprolin activation by resveratrol inhibits the proliferation and metastasis of colorectal cancer cells
}

\author{
SE-RA LEE ${ }^{1,2^{*}}$, HUA JIN ${ }^{3 *}$, WON-TAE KIM ${ }^{1}$, WON-JUNG KIM ${ }^{1}$, \\ SUNG ZOO KIM ${ }^{3}$, SUN-HEE LEEM ${ }^{1}$ and SOO MI KIM ${ }^{3}$ \\ ${ }^{1}$ Department of Biological Science, Dong-A University, Busan 49315; ${ }^{2}$ Division of Drug Development Optimization, \\ Osong Medical Innovation Foundation (KBio), Osong, Chungbuk 28160; ${ }^{3}$ Department of Physiology, \\ Institute of Medical Science, Chonbuk National University Medical School, Jeonju, Jeonbuk 54907, Republic of Korea
}

Received November 10, 2017; Accepted May 25, 2018

DOI: $10.3892 /$ ijo.2018.4453

\begin{abstract}
Resveratrol (RSV) is a polyphenolic compound that naturally occurs in grapes, peanuts and berries. Considerable research has been conducted to determine the benefits of RSV against various human cancer types. Tristetraprolin (TTP) is an AU-rich element-binding protein that regulates mRNA stability and has decreased expression in human cancer. The present study investigated the biological effect of RSV on TTP gene regulation in colon cancer cells. RSV inhibited the proliferation and invasion/metastasis of HCT116 and SNU81 colon cancer cells. Furthermore, RSV induced a dose-dependent increase in TTP expression in HCT116 and SNU81 cells. The microarray experiment revealed that RSV significantly increased TTP expression by downregulating E2F transcription factor 1 (E2F1), a downstream target gene of TTP and regulated genes associated with inflammation, cell proliferation, cell death, angiogenesis and metastasis. Although TTP silencing inhibited TTP mRNA expression, the expression was subsequently restored by RSV. Small interfering RNA-induced TTP inhibition attenuated the effects of RSV on cell growth. In addition, RSV induced the mRNA-decaying activity of TTP and inhibited the relative luciferase activity of baculoviral IAP repeat containing 3 (cIAP2), large tumor suppressor kinase 2 (LATS2), E2F1, and lin-28 homolog A (Lin28) in HCT116 and SNU81 cells. Therefore, RSV enhanced the inhibitory activity of TTP in
\end{abstract}

Correspondence to: Dr Soo Mi Kim, Department of Physiology, Institute of Medical Science, Chonbuk National University Medical School, 20 Gungiro, Deokjin-Gu, Jeonju, Jeonbuk 54907, Republic of Korea

E-mail: soomikim@jbnu.ac.kr

Dr Sun-Hee Leem, Department of Biological Science, Dong-A University, 37 Nakdong-Daero 550-Beon-gil, Saha-Gu, Busan 49315, Republic of Korea

E-mail: shleem@dau.ac.kr

*Contributed equally

Key words: resveratrol, colon cancer cells, tristetraprolin, metastasis, invasion, cell proliferation
HCT116 and SNU81 cells by negatively regulating cIAP2, E2F1, LATS2, and Lin28 expression. In conclusion, RSV suppressed the proliferation and invasion/metastasis of colon cancer cells by activating TTP.

\section{Introduction}

Colorectal cancer is one of the most common cancer types worldwide and the second most lethal cancer in the USA (1); its incidence has been increasing in Asian countries, including South Korea, and it has become a severe public health problem worldwide (2-4). Although surgery remains the most effective treatment for patients with colorectal cancer, the majority of patients experience relapse within 5 years following complete surgical resection (5-7). Given the heterogeneous properties of colorectal cancer tumors, patients with colorectal cancer have a poor overall survival in response to treatment $(8,9)$. In addition, similar histopathological tumors may elicit considerably different clinical courses $(10,11)$. Therefore, for improved treatment and management of patients with colorectal cancer, knowledge of each cancer property that is associated with the differential responses to drug treatment is imperative for predicting patient outcomes and developing novel therapeutic targets may be beneficial.

Resveratrol (3,5,4'-trihydroxystilbene; RSV) is a polyphenolic compound that naturally occurs in grapes, peanuts and berries (12). Considerable research has been conducted to determine the benefits of RSV against various human cancer types (12-16). RSV has anti-proliferative properties against numerous cancer types, including those of the liver, breast, prostate, lung and colorectum (13,17-22). RSV induces apoptosis and inhibits cell growth, cell cycle progression, migration and invasion $(19,22)$. RSV has antitumor effects in colorectal cancer by inhibiting various carcinogenic processes (21,23-26). Gong et al (27) demonstrated that RSV inhibited colorectal cancer proliferation by suppressing cyclooxygenase-2 (COX-2) expression. Karimi Dermani et al (28) reported that RSV inhibited proliferation, invasion and epithelial-mesenchymal transition by increasing miR-200c expression in HCT-116 colorectal cancer cells. Furthermore, sirtuin 1 is required for RSV-mediated chemopreventive effects in colorectal cancer cells (29). Hence, RSV serves an important role in colorectal 
cancer. However, the precise molecular mechanism underlying the effect of RSV on colorectal cancer has not been clearly understood.

Tristetraprolin (TTP) is an AU-rich element (Res)-binding protein that regulates mRNA stability (30) and is a key protein involved in regulating cytokine expression (31). Decreased TTP expression is observed in patients with colorectal, lung, breast and pancreatic cancer, and TTP dysfunction serves as an important indicator of cancer development (32-37). TTP suppresses the growth of human colon cancer cells by regulating vascular endothelial growth factor expression (38). Recent studies have addressed the association between RSV and TTP in cancer. Ryu et al (39) reported that RSV induced apoptosis by activating TTP in glioma cells, whereas RSV inhibited MCF-7 cell proliferation by upregulating TTP (31). However, the precise association between TTP and RSV in colorectal cancer has not been completely understood. The present study reports for the first time, to the best of our knowledge, that RSV induced apoptosis in colorectal cancer cells by activating TTP. RSV-induced TTP expression inhibited baculoviral IAP repeat containing 3 (cIAP2), large tumor suppressor kinase 2 (LATS2), E2F transcription factor 1 (E2F1), and lin-28 homolog A (Lin28) and MDM2 protooncogene (MDM2) mRNAs by binding to their 3 ' untranslated regions (3'UTRs). Furthermore, RSV-induced TTP upregulation inhibited the cell proliferation and metastasis of human colorectal cells. The results of the present study may increase understanding of the antitumor effects of RSV and suggest future applications for RSV as an anticancer agent in clinical cancer therapy.

\section{Materials and methods}

Cell lines and reagents. Colorectal cancer cells (HCT116 and SNU81) were purchased from the Korean Cell Line Bank (Seoul, Korea) and maintained in RPMI-1640 medium supplemented with $10 \%$ fetal bovine serum (FBS) and $1 \%$ penicillin-streptomycin (all Capricorn Scientific $\mathrm{GmbH}$, Ebsdorfergrund, Germany) at $37^{\circ} \mathrm{C}$ in a humidified $5 \% \mathrm{CO}_{2}$ atmosphere. RSV was purchased from Sigma-Aldrich (Merck KGaA, Darmstadt, Germany; cat. no. 274666) and suspended in dimethyl sulfoxide (DMSO; cat. no. D2650; Sigma-Aldrich; Merck KGaA). Colorectal cancer cells were treated with RSV in medium containing $2.5 \%$ FBS for $24 \mathrm{~h}$ at $37^{\circ} \mathrm{C}$.

Plasmid construction and luciferase assay. The pGL3/ TTPp-1411 promoter construct (40) and variable target gene of TTP in the psiCHECK2 luciferase reporter constructs [psiCHECK2/cIAP2 (41), E2F1 (42), LATS2 (43), Lin28 (44) and MDM2 3'UTR constructs] were as previously described. Cells were transfected with various types of plasmid constructs using iN-fect ${ }^{\mathrm{TM}}$ in vitro transfection reagent (Intron Biotechnology, Inc., Seongnam, Korea). For the luciferase assays, HCT116 and SNU81 cells were seeded $1 \times 10^{5}$ cells/well in a 12-well plate and transfected with the constructs (500 ng) for $24 \mathrm{~h}$, and treated with RSV $(5,10$ and $20 \mu \mathrm{M})$ for $24 \mathrm{~h}$. Transfected cells were lysed with a lysis buffer (Promega Corporation, Madison, WI, USA) and mixed with the luciferase assay reagent (Promega Corporation). The chemilu- minescent signal was measured using the Wallac Victor 1420 multilabel counter (PerkinElmer Inc., Waltham, MA, USA). In each sample, the firefly luciferase activity was normalized to the Renilla luciferase activity. All luciferase assays reported herein represent at least three independent experiments, each comprising three wells per transfection.

SDS-PAGE and immunoblotting. The total protein was extracted from HCT116 and SNU81 cells using ice-cold radioimmunoprecipitation assay buffer $[50 \mathrm{mM}$ Tris $\mathrm{HCl}, \mathrm{pH}$ 7.4; 150 mM NaCl; 1 mM EDTA; $1 \%$ (v/v) Triton X-100; 0.1\% (w/v) SDS] and a protease inhibitor cocktail (Roche Diagnostics $\mathrm{GmbH}$, Mannheim, Germany). Protein concentrations were determined using the bicinchoninic acid assay, according to the manufacturer's protocol (Thermo Fisher Scientific, Inc., Waltham, MA, USA). The protein samples $(10 \mu \mathrm{g})$ were loaded onto a $10 \%$ SDS-PAGE gel, and transferred onto Hybond-P membranes (GE Healthcare Bio-Sciences, Pittsburgh, PA, USA). Membranes were blocked using 5\% skim milk for $1 \mathrm{~h}$ at room temperature and probed using appropriate dilutions of rabbit anti-human TTP (cat. no. T5327; Sigma-Aldrich; Merck KGaA; $1: 3,000$ ) and anti- $\beta$-actin (cat. no. A2228, Sigma-Aldrich; Merck KGaA; 1:3,000) antibodies overnight at $4^{\circ} \mathrm{C}$. Secondary antibody rabbit-IgG (cat. no. ADI-SAB-300; Enzo Life Sciences, Inc., Farmingdale, NY, USA; 1:5,000) was probed for $90 \mathrm{~min}$ at room temperature. Immunoreactivity was determined using an enhanced chemiluminescence detection system (GE Healthcare Bio-Sciences). Films were exposed at multiple time points to ensure that the images were not saturated. ImageJ (v.1.51j8; National Institutes of Health, Bethesda, MD, USA) was used to analyze the blot images.

Reverse transcription-quantitative polymerase chain reaction $(R T-q P C R)$. RNA isolation was performed using TRIzol reagent (Thermo Fisher Scientific, Inc.) and was synthesized to cDNA using Moloney murine leukemia virus reverse transcriptase kit (cat. no. 3201; Beams Biotechnology, Seongnam, Korea) and Oligo-dT primer (cat. no. 79237, Qiagen, Hilden, Germany), according to manufacturer's protocol for $60 \mathrm{~min}$ at $37^{\circ} \mathrm{C}$. For the PCR $(5 \mu \mathrm{l})$, the cDNA product, PCR master mix (cat. no. RT500; Enzynomics, Inc., Daejeon, Korea), and a Bio-Rad system (CFX96 Optics Module; Bio-RadLaboratories, Inc., Hercules, CA, USA) were used while monitoring, in realtime, the increase in the fluorescence of the SYBR Green dye (cat. RT500, Enzynomics Co., Ltd., Daejeon, Korea). The specificity of each primer pair was confirmed by melting curve analysis $(45,46)$. The PCR primer pairs used were as follows: TTP, CGCTACAAGACTGAGCTAT and GAGGTAGAACTT GTGACAGA; $\beta$-actin, CCCTGGAGAAGAGCTACGAG and AGGTAGTTTCGTGGATGCCA. PCR cycling conditions were $94^{\circ} \mathrm{C}$ for $10 \mathrm{~min}$ to activate the DNA polymerase, followed by 40 cycles of $94^{\circ} \mathrm{C}$ for $15 \mathrm{sec}, 60^{\circ} \mathrm{C}$ for $30 \mathrm{sec}$, and $72^{\circ} \mathrm{C}$ for $30 \mathrm{sec}$.

MTT assay. For the MTT assay, $1 \times 10^{4}$ cells/well were seeded in 96-well culture plates with complete RPMI-1640 medium. The cells were subsequently incubated with different RSV concentrations $(10,20$ or $50 \mu \mathrm{M})$ for up to $72 \mathrm{~h}$. The culture medium was removed, and the cells were incubated with MTT ( $5 \mathrm{mg} / \mathrm{ml}$; Sigma-Aldrich; Merck KGaA) for $90 \mathrm{~min}$ at 
$37^{\circ} \mathrm{C}$. Following incubation for $90 \mathrm{~min}$, the MTT solution was removed, and the formazan product was extracted and diluted with DMSO (cat. no. D2650; Sigma-Aldrich; Merck KGaA) with gentle agitation for $15 \mathrm{~min}$. The absorbance was measured using the VICTOR3 Multilabel Reader 1420 (PerkinElmer) at $490 \mathrm{~nm}$. Three independent experiments were performed in four duplicated wells.

Migration and invasion assay. The effect of RSV on the invasive properties of HCT116 and SNU81 cells was assessed using Boyden chambers (Neuro Probe, Inc., Gaithersburg, MD, USA) that were precoated with Matrigel (BD Biosciences, Franklin Lakes, NJ, USA) and incubated for $1 \mathrm{~h}$ at room temperature. The bottom wells were filled with $28 \mu \mathrm{l}$ medium with $2 \%$ serum. In total, $1 \times 10^{5}$ cells $/ 56 \mu 1$ were seeded into the upper compartment and incubated for $24 \mathrm{~h}$ at $37^{\circ} \mathrm{C}$ and $5 \% \mathrm{CO}_{2}$. Following incubation for $24 \mathrm{~h}$, the cells attached to the upper surface of the filter were removed using a cotton swab, and those attached to the lower surface were stained using Diff-Quik reagents (Sysmex Corporation, Kobe, Japan) for $3 \mathrm{~min}$ at room temperature and counted (five fields/well). The invasion percentage was expressed as the percentage of invading cells through the Matrigel. A representative graph of six independent experiments is presented. Images from each well were immediately captured using the Axiovert $40 \mathrm{CFL}$ inverted fluorescence microscope (Carl Zeiss AG, Oberkochen, Germany) in five random fields at $\mathrm{x} 40$ magnification. For the migration assay, the membrane was pre-coated with collagen (cat. no. C7661; Sigma-Aldrich; Merck KGaA) and $10 \%$ acetic acid for $1 \mathrm{~h}$ at room temperature.

Clonogenic assay. HCT116 and SNU81 cells were seeded into 12-well plates at $1 \times 10^{4}$ cells/well and incubated for $24 \mathrm{~h}$ at $37^{\circ} \mathrm{C}$ and $5 \% \mathrm{CO}_{2}$. The cells were subsequently treated with $\mathrm{RSV}$ in a dose-dependent manner and incubated for 10 days at $37^{\circ} \mathrm{C}$ and $5 \% \mathrm{CO}_{2}$. Fresh medium containing RSV (5, 10 and $20 \mu \mathrm{M}$ ) was added on the $3 \mathrm{rd}$ day. On the 10th day, the medium was removed from the plates, and the cells were washed once with PBS. The colonies were fixed and stained with methanol $(25 \% \mathrm{v} / \mathrm{v})$ that contained crystal violet $(0.05 \% \mathrm{w} / \mathrm{v})$ for $30 \mathrm{~min}$ at room temperature. Thereafter, the residual staining solution was removed, and the plates were washed with water. When the plates had been rinsed three times with PBS and air-dried, the colonies were counted using ImageJ.

siRNA transfection and treatments. TTP small interfering RNA (siRNA; cat. no. sc-36760) or control siRNA (cat. no. sc-37007; both Santa Cruz Biotechnology, Inc., Dallas, TX, USA) was transfected (100 nM) into HCT116 and SNU81 cells using Lipofectamine ${ }^{\circledR} 2000$ (Invitrogen; Thermo Fisher Scientific, Inc.), according to the manufacturer's protocol. After $24 \mathrm{~h}$, cells were treated with RSV $(20 \mu \mathrm{M})$ for $24 \mathrm{~h}$.

Microarray. The mirVana ${ }^{\mathrm{TM}}$ miRNA isolation labeling kit (Ambion; Thermo Fisher Scientific, Inc.) was used for isolating total RNA from the HCT116 cells at $90 \%$ confluence, according to the manufacturer's protocol. The Illumina Total Prep RNA amplification kit (Illumina, Inc., San Diego, CA, USA) was used for hybridization with biotin-labeled cRNA. Illumina Human-12 BeadChip V.4 microarray (Illumina, Inc.) was used for hybridizing samples, and data were extracted using the Genome Studio (Illumina, Inc.). R software (R-3.50; http://crans.us.r-project.org) was used for data analysis, and the Cluster 3.0 (Eisen Lab; University of California Berkeley, Berkeley, CA, USA) and Treeview (Eisen Lab; University of California Berkeley) software packages were used for generating the gene expression heat map.

Statistics. GraphPad Prism 5.0 (GraphPad Software, Inc., La Jolla, CA, USA) was used for all statistical analyses. Data are presented as the mean \pm standard deviation. Comparisons among the groups were performed by paired Student's t-test and a two-way analysis of variance with Duncan's multiple range test. $\mathrm{P}<0.05$ was considered to indicate a statistically significant difference.

\section{Results}

$R S V$ suppresses colon cancer cell proliferation. To investigate the effect of RSV on colorectal cancer progression, MTT and clonogenic assays were performed. The MTT assay demonstrated that treatment with RSV had a dose-dependent inhibitory effect on HCT116 and SNU81 cell viability (Fig. 1A). The clonogenic assay additionally demonstrated that treatment with RSV significantly inhibited HCT116 and SNU81 cell proliferation in a dose-dependent manner (Fig. 1B). Therefore, RSV inhibited the progression and proliferation of colorectal cancer cells.

$R S V$ suppresses the invasive and migratory effects of colon cancer cells. The effect of RSV on the migration and invasion of colorectal cancer cells was also investigated. RSV-treated HCT116 and SNU81 cells were assessed using Matrigel invasion and collagen migration assays. RSV significantly inhibited the invasive ability of colorectal cancer cells in a dose-dependent manner (Fig. 2A). The migration assay also confirmed that RSV significantly inhibited the migratory ability of colorectal cancer cells in dose-dependent manner (Fig. 2B). Therefore, these results suggested that RSV inhibited the migration and invasion of colorectal cancer cells.

Microarray data reveal an $R S V$-induced increase in TTP gene expression. To investigate the effect of RSV on gene expression levels in colorectal cancer cells, the microarray experiment was performed. RSV administration significantly regulated several genes associated with inflammation, proliferation, cell death, angiogenesis and metastasis (Fig. 3). Increased ZFP36 (TTP) gene expression was observed in RSV-treated HCT116 cells. In addition, RSV decreased the expression of the oncogenes Myc proto-oncogene (Myc), KRAS proto-oncogene GTPase (KRAS) and Fos proto-oncogene AP-1 transcription factor subunit (FOS), and the downstream target genes of TTP, including E2F1. Therefore, RSV-induced TTP upregulation may inhibit the growth and metastasis of colorectal cancer cells.

$R S V$ induces the mRNA and protein expression of TTP. The present study further determined the endogenous mRNA and protein expression levels of TTP in HCT116 and SNU81 cells using RT-qPCR and western blot analysis (Fig. 4A). 
A

HCT116

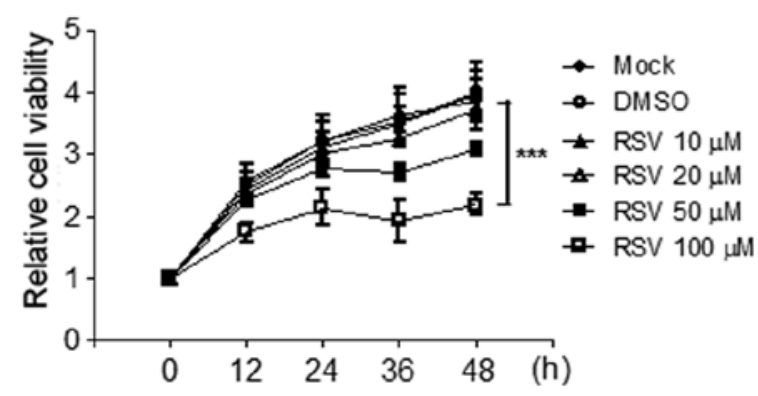

SNU81

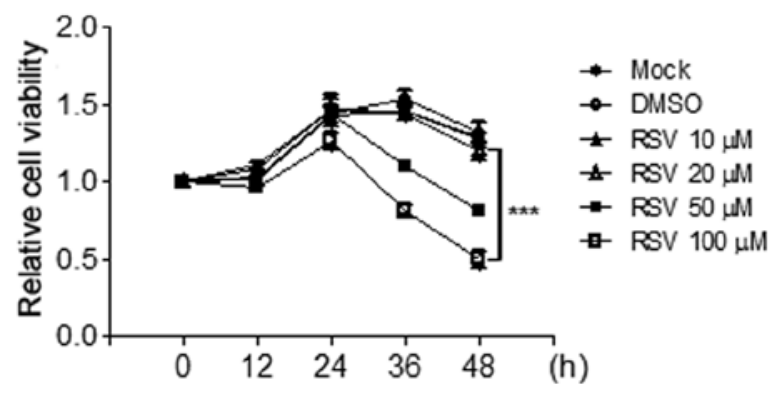

B
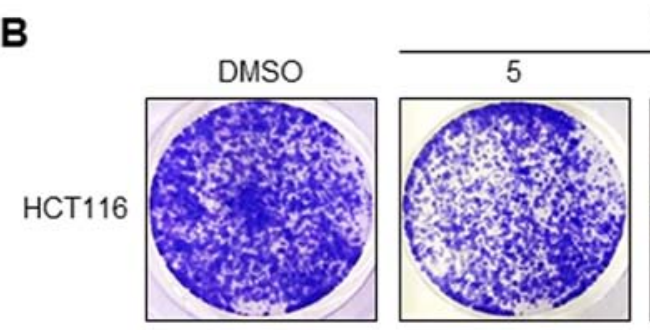

Resveratrol $(\mu \mathrm{M})$
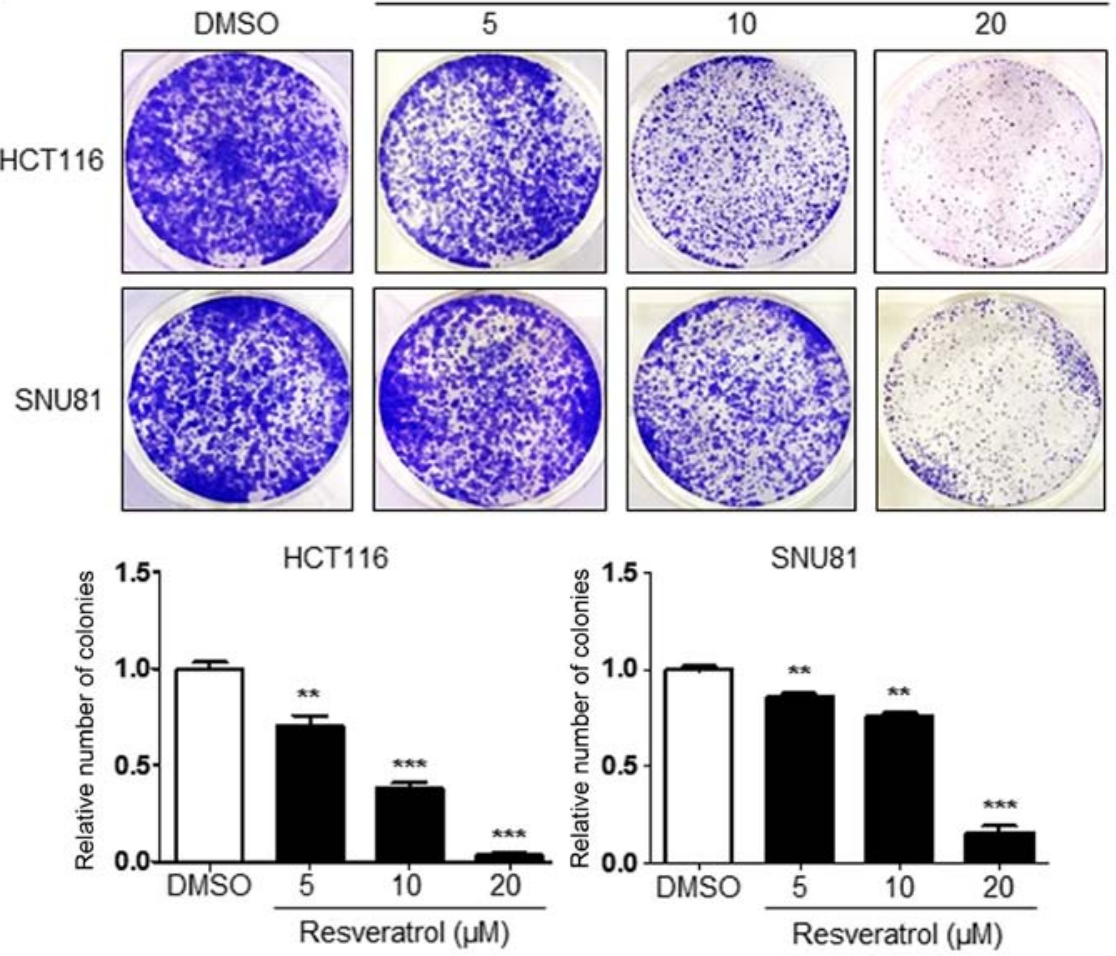

Figure 1. RSV suppresses the proliferation of colorectal cancer cells. (A) Regulation of TTP expression by RSV and suppression of tumor progression in cancer cells. MTT assays demonstrated a decline in cancer cell viability in HCT116 and SNU81 cells treated with RSV, in a dose-dependent manner. Data are presented as the mean \pm SD of three different experiments. ${ }^{* * *} \mathrm{P}<0.001$. (B) A clonogenic assay was performed on HCT116 and SNU81 cells treated with RSV at increasing doses in order to assess proliferation. Colonies were counted under a light microscope and were photographed. Data are presented as the mean \pm SD of three different experiments. ${ }^{* *} \mathrm{P}<0.01 ;{ }^{* * *} \mathrm{P}<0.001$ vs. DMSO. RSV, resveratrol; TTP, tristetraprolin; DMSO, dimethyl sulfoxide; SD, standard deviation.

Endogenous mRNA and protein expression levels of TTP were increased in HCT116 and SNU81 cells (Fig. 4A). In addition, siTTP decreased the mRNA and protein levels of TTP in HCT116 and SNU81 cells (Fig. 4A). To determine whether RSV regulated TTP expression in colorectal cancer cells, HCT116 and SNU81 cells were treated with 0, 10, 20 and $50 \mu \mathrm{M}$ RSV. RSV significantly increased the mRNA and protein expression levels of TTP in HCT116 and SNU81 cells in a dose-dependent manner (Fig. 4B). In particular, $>20 \mu \mathrm{M}$ RSV significantly increased TTP expression in colorectal cancer cells (Fig. 4B). To further test whether RSV regulates TTP expression, HCT116 and SNU81 cells were transfected with scramble RNA or siTTP (100 nM). It was observed that RSV restored TTP mRNA expression in HCT116 and SNU81 cells whose TTP expression was reduced by siTTP (Fig. 4C).
Treatment with RSV reversed the inhibition of TTP expression. In addition, siRNA-induced TTP inhibition attenuated the effects of RSV on the cell growth of HCT116 and SNU81 cells (Fig. 4D). Therefore, these data indicate that TTP mediated the apoptotic effects of RSV in colorectal cancer cells and that RSV induced TTP expression in colorectal cancer cells.

$R S V$ controls the downstream target gene of TTP. The present study further assessed whether RSV increased TTP promoter activity in a reporter assay. HCT116 and SNU81 cells were transiently transfected with a pGL3/hTTPp-1411 construct, followed by treatment with RSV. Following treatment with RSV for $24 \mathrm{~h}$, the luciferase activity was measured, revealing significantly increased TTP promoter activity in HCT116 and 

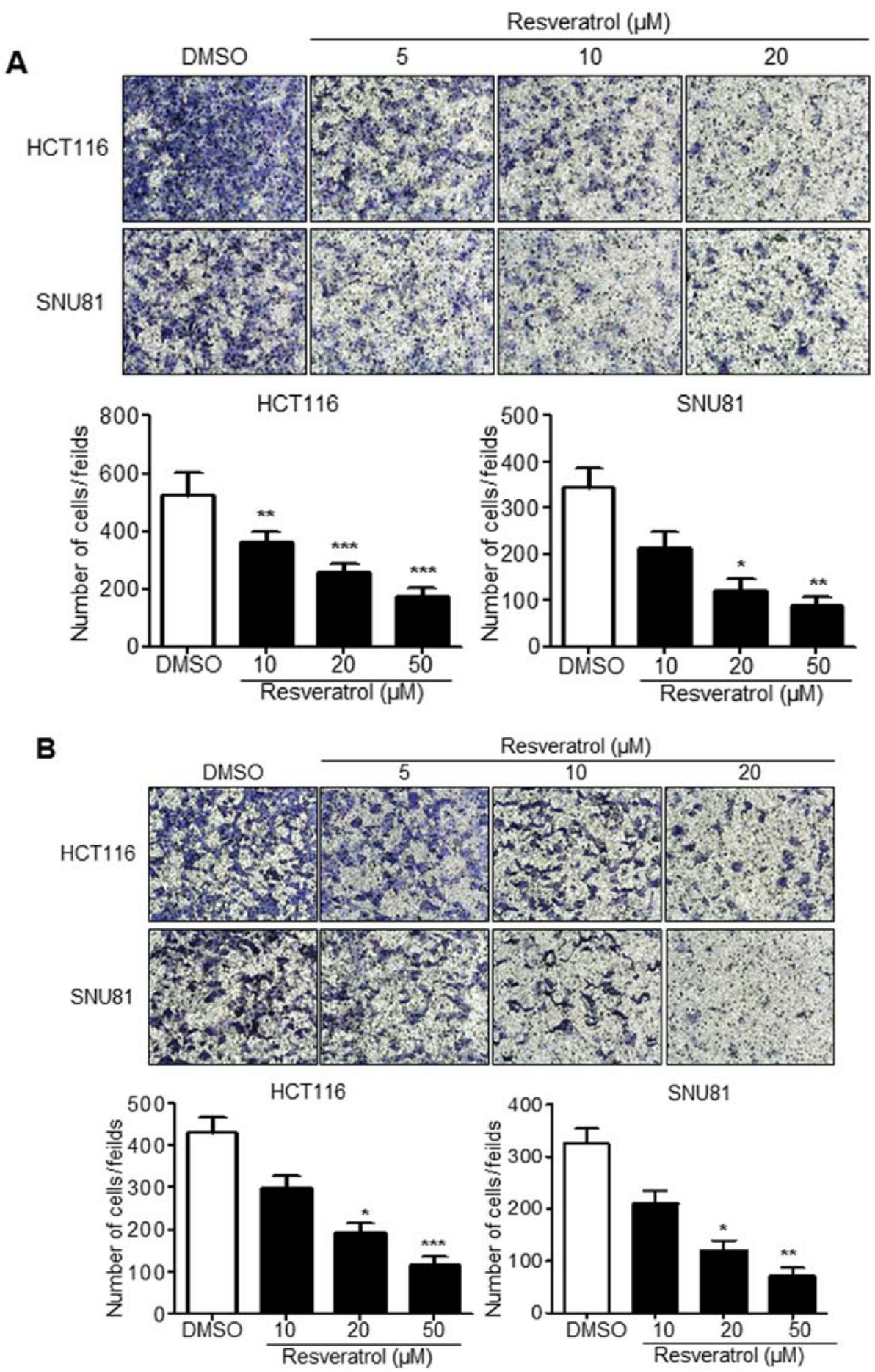

Resveratrol $(\mu \mathrm{M})$
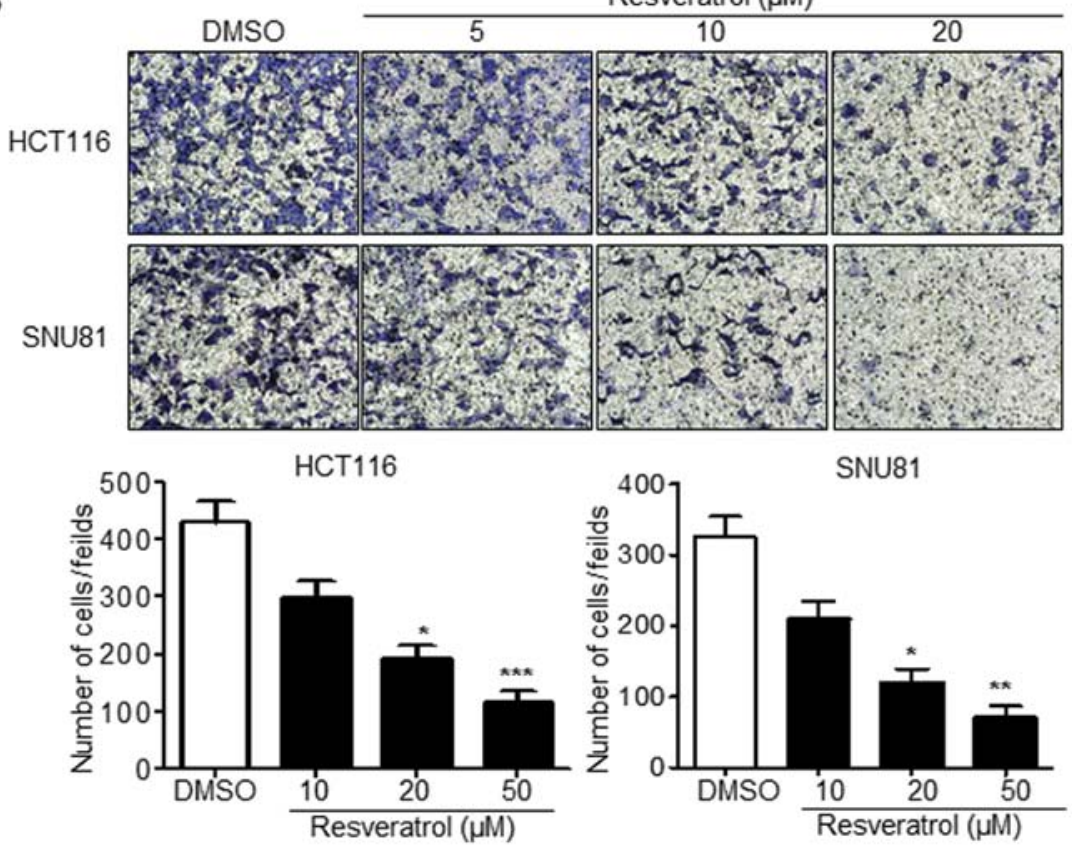

Figure 2. RSV inhibits the invasion and metastasis of colorectal cancer cells. (A) Invasion assay. HCT116 and SNU81 cells were treated with RSV, following which the percentage of invasive and migratory cells was determined. TTP suppressed the invasion and migration of colon cancer cells following treatment with RSV in a dose-dependent manner, as observed in the Boyden chamber assay. Graphical representations of the results for HCT116 and SNU81 cells are presented. (B) Migration assay. The in vitro invasive properties of HCT116 and SNU81 cells were assessed using Boyden chambers. Invading cells were visualized by membrane staining using Diff-Quik solution and counted (five fields/well). Graphical representation of the results for HCT116 and SNU81 cells are presented. Magnification, $\mathrm{x} 100 .{ }^{*} \mathrm{P}<0.05 ;{ }^{* * *} \mathrm{P}<0.01 ;{ }^{* * *} \mathrm{P}<0.001$ vs. DMSO. DMSO, dimethyl sulfoxide; TTP, tristetraprolin; RSV, resveratrol.

SNU81 cells (Fig. 5A). Given a previous finding (41-44) that TTP reduced cIAP2, E2F1, LATS2 and Lin28 expression, and inhibited cancer cell growth, the present study subsequently investigated whether RSV regulates the promoter activities of cIAP2, E2F1, LATS2 and Lin28, which bind with TTP in colorectal cancer cells. HCT116 and SNU81 cells were transfected with luciferase reporter constructs that incorporated the 3'UTRs of cIAP2, E2F1, LATS2 and Lin28 mRNA
(psiCHECK2/cIAP2, psiCHECK2/E2F1, psiCHECK2/ LATS2 and psiCHECK2/Lin28). Each transfected cell was treated with RSV $(20 \mu \mathrm{M})$, and the luciferase activity was measured $24 \mathrm{~h}$ post-treatment. Consistent with previous studies, the induction of TTP expression reduced the luciferase activities of cIAP2, E2F1, LATS2 and Lin28 in HCT116 and SNU81 cells (Fig. 5B). RSV enhanced the inhibitory activity of TTP on target genes in HCT116 and SNU81 cells (Fig. 5B). 


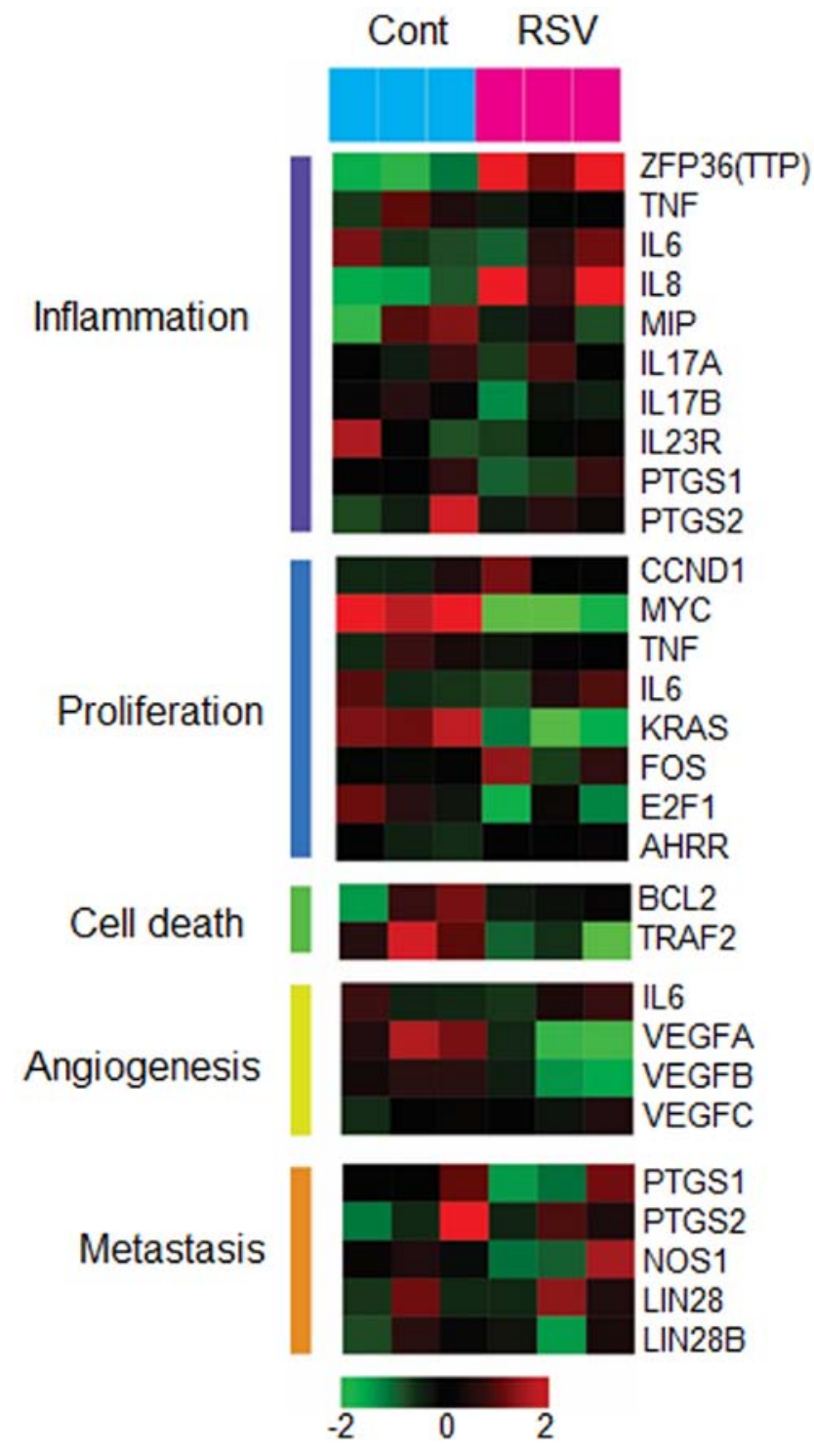

Figure 3. Microarray heat map demonstrating the effect of RSV on genes associated with inflammation, proliferation, cell death, angiogenesis and metastasis in HCT116 cells. Data are presented in matrix format with rows indicating the individual gene and columns indicating each sample. Red and green represent upregulated and downregulated gene expression levels, respectively, as indicated in the scale bar ( $\log 2$ transformed). RSV, resveratrol; Cont, control; ZFP36, ZFP36 ring finger protein; TNF, tumor necrosis factor; IL, interleukin MIP, major intrinsic protein of lens fiber; PTGS, prostaglandin-endoperoxide synthase; CCND1, cyclin D1; MYC, Myc proto-oncogene; KRAS, KRAS protooncogene GTPase; FOS, Fos proto-oncogene AP-1 transcription factor subunit; E2F transcription factor 1; AHRR, aryl-hydrocarbon receptor repressor; BCL2, apoptosis regulator Bcl-2; TRAF2, TNF receptor associated factor 2; VEGF, vascular endothelial growth factor; NOS1, nitric oxide synthase 1; LIN28, lin-28 homolog A; LIN28B, lin-28 homolog B.

In addition, siTTP increased mRNA and protein levels of E2F1 in HCT116 and SNU81 cells (Fig. 5C). Therefore, our results indicated that RSV induces TTP expression and its target gene mRNA-decaying activity in colorectal cancer cells.

\section{Discussion}

Despite the fact that RSV has been studied in various human cancers, its biological effects on colorectal cancer have not been fully elucidated. The present study aimed to investigate the effects of RSV in human colorectal cancer cells and to elucidate its effect on regulating TTP expression. Although TTP serves key roles in cancer cells, TTP regulation by RSV in colorectal cancer cells is yet to be clearly investigated. The present study demonstrated that RSV inhibited cell proliferation and invasion/metastasis by activating TTP in human colorectal cancer cells.

Phytochemicals are promising therapeutic agents for cancer treatment. RSV, a natural compound occurring in grapes, peanuts and berries, has anticancer properties against a number of types of cancer, including colorectal cancer $(28,47,48)$. RSV induces cellular apoptosis, and decreases migration and invasion, by regulating a number of mechanisms in colorectal cancer cells $(28,29,47,48)$. Du et al (47) accordingly reported that the inhibitory effect of RSV on colorectal cancer cells was mediated by the hedgehog/GLI family zinc finger 1 signaling pathways. Feng et al (48) demonstrated that treatment with RSV inhibits proliferation and induces apoptosis in human colon cancer cells. Furthermore, Buhrmann et al (29) demonstrated that RSV suppresses the tumorigenesis of colorectal cancer cells by targeting sirtuin 1 and suppressing nuclear factor- $\kappa \mathrm{B}$ activation. In addition, RSV has been comprehensively investigated with respect to its role in cell cycle regulation in colorectal cancer. RSV upregulated cyclin dependent kinase inhibitor 1A, causing cell-cycle arrest at the $\mathrm{G}_{0} / \mathrm{G}_{1}$ and $\mathrm{G}_{2} / \mathrm{M}$ phases, and the activation of the caspase-dependent cyclin/cyclin dependent kinase pathway in colon cancer cells $(49,50)$. Therefore, RSV appears to have antitumor properties in colorectal cancer cells by targeting various signaling pathways. Consistent with previous studies, the present results indicated that RSV inhibited the viability of HCT116 and SNU81 cells in a dose- and timedependent manner. RSV also significantly inhibited the colony formation of HCT116 and SNU81 cells in a dose-dependent manner. These observations are in accordance with previous studies $(28,29,47,48)$ that demonstrated that RSV negatively regulates the growth of colorectal cancer cells. In addition, RSV significantly reduced the invasion and metastasis of colorectal cancer cells (HCT116 and SNU81 cells) in a dosedependent manner. These results regarding RSV regulation of cell mobility and adhesion, and the inhibition of invasion and metastasis in colorectal cancer cells, were consistent with those of previous studies $(28,29,47,48)$.

An increasing number of studies have validated the importance of TTP expression in human cancer (51-54). The loss of TTP gene expression has been reported in various cancer types $(51,53)$, and reduced TTP gene expression has been demonstrated to lead to cancer development $(32,33,55)$. Therefore, TTP overexpression may be a novel strategy for cancer prevention. TTP also serves an important role in a number of cancer types, including colon cancer. TTP inhibits IL-23 expression (56) and downregulates vascular endothelial growth factor (VEGF) and COX-2 expression in human colon cancer $(38,57)$. Accordingly, TTP expression may be controlled via the aforementioned signaling pathways. Therefore, examining whether RSV regulates TTP expression in colorectal cancer cells is essential. To investigate the association between RSV and TTP gene expression in colorectal cancer cells (HCT116), gene expression profiling was performed. The microarray experiment demonstrated that RSV significantly 
A

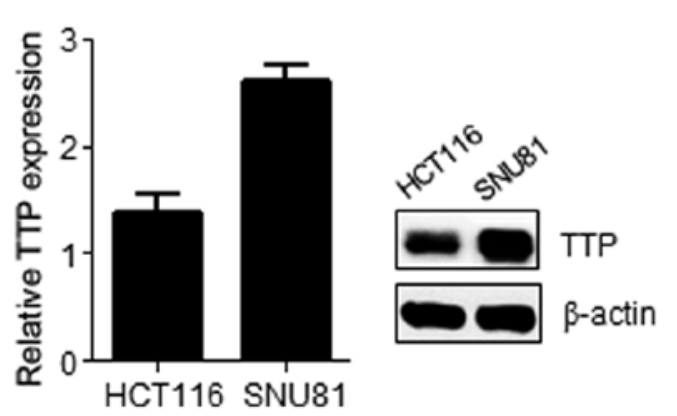

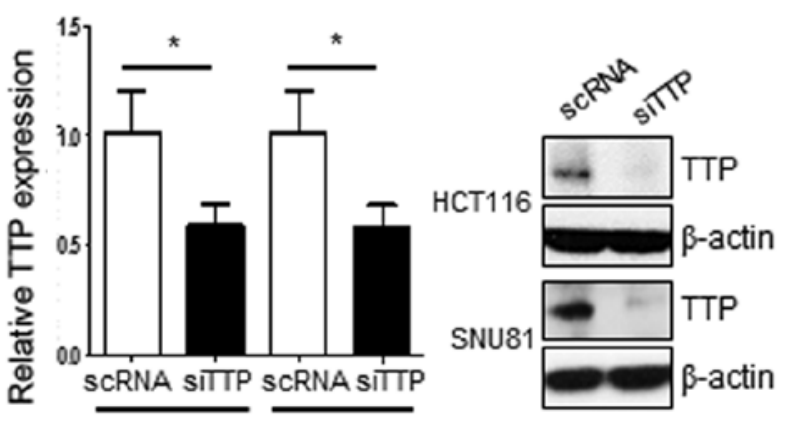

B

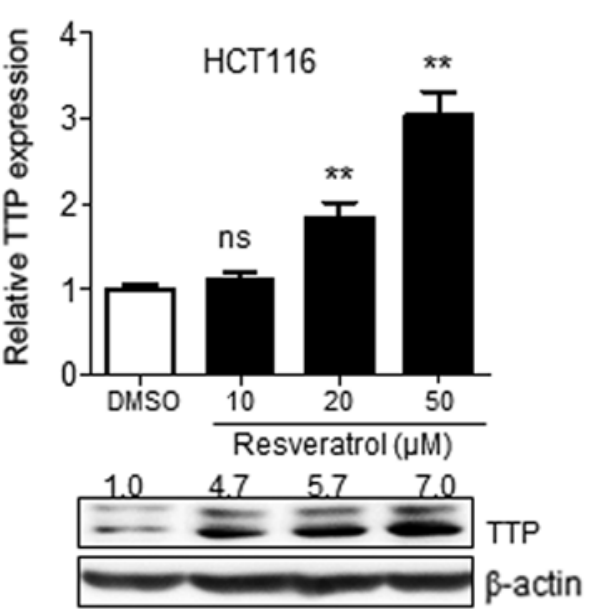

C

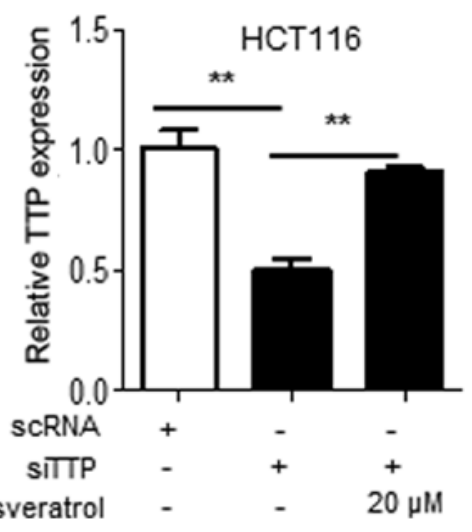

D

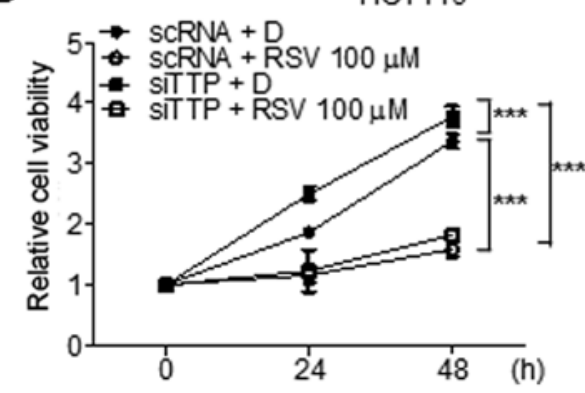

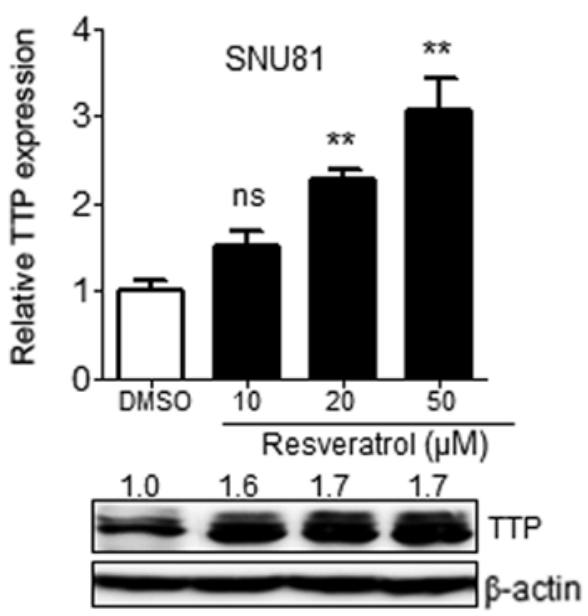

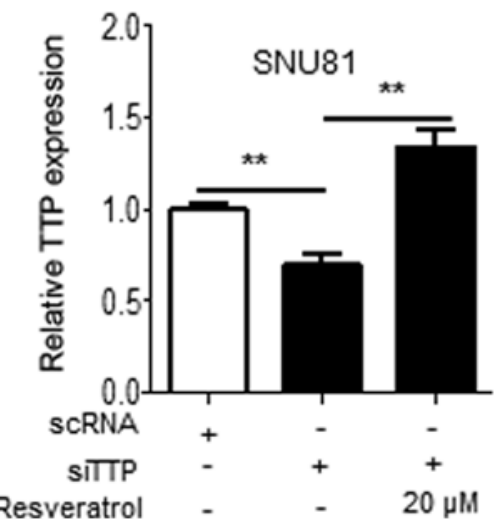

SNU81

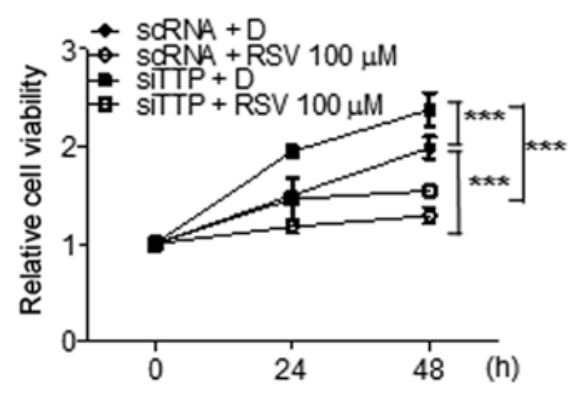

Figure 4. RSV induces TTP expression in colorectal cancer cells. (A) Endogenous mRNA and protein expression levels of TTP in colon cancer cells (HCT116 and SNU81). "P<0.05. (B) RSV induced the mRNA and protein expression of TTP in a dose-dependent manner in HCT116 and SNU81 cells. $\beta$-actin was detected as the loading control for RT-qPCR and western blotting. The relative protein expression level was calculated as a ratio of the control (DMSO), using ImageJ software to detect the intensity of the protein band. ${ }^{* *} \mathrm{P}<0.01$ vs. DMSO. (C) RSV restored TTP expression in cell lines whose TTP expression was reduced by TTP siRNA. HCT116 and SNU81 cells were transfected with scRNA or TTP siRNA (100 nM). After $24 \mathrm{~h}$, DMSO or RSV ( $20 \mu \mathrm{M})$ was added to the cells, followed by RNA extraction after $24 \mathrm{~h}$. $\beta$-actin was detected as the loading control for RT-qPCR. Each bar represents the mean \pm SD of three independent experiments. "* $\mathrm{P}<0.01$. (D) Cell survival was assessed using the MTT assay. Cell viability relative to that of the control is expressed as the mean \pm SD of three independent experiments. ${ }^{* * *} \mathrm{P}<0.001$. TTP, tristetraprolin; RSV, resveratrol; RT-qPCR, reverse transcription-quantitative polymerase chain reaction; si, small interfering; DMSO, dimethyl sulfoxide; ns, not significant; SD, standard deviation; sc, scramble. 
A

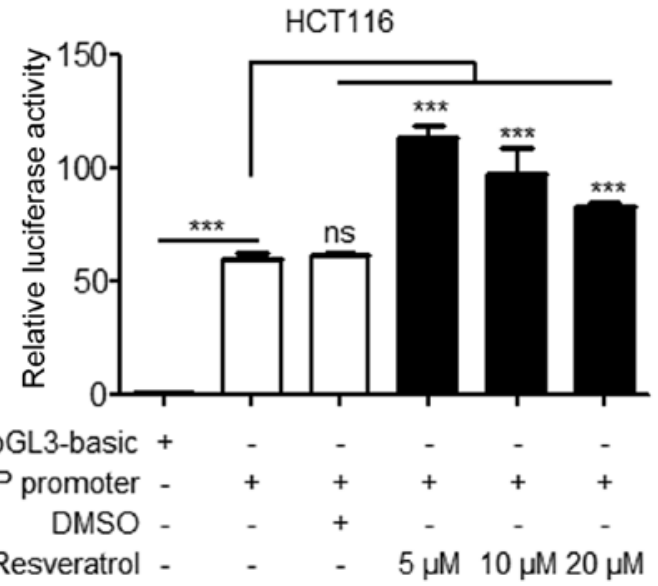

Resveratrol - $\quad$ - $\quad$ - $5 \mu \mathrm{M} 10 \mu \mathrm{M} 20 \mu \mathrm{M}$

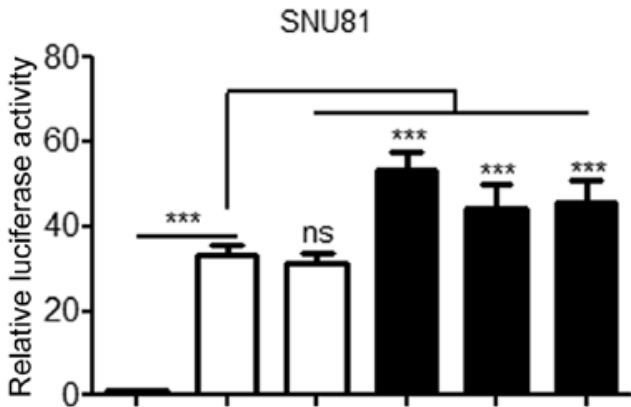

pGL3-basic +

TTP promoter -

DMSO -

\section{B}

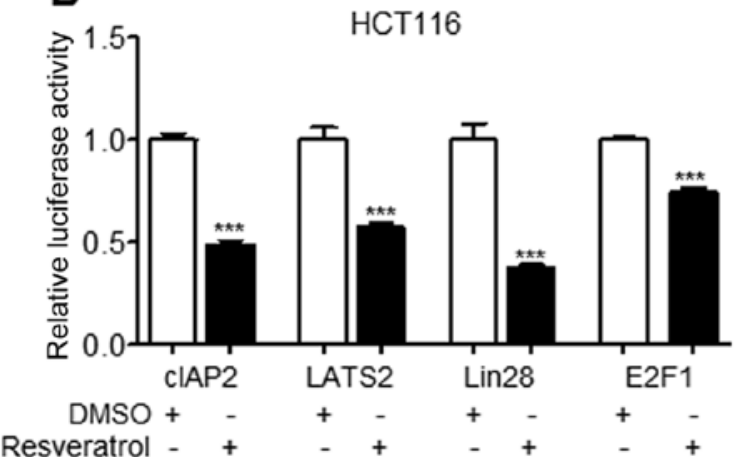

\section{C}

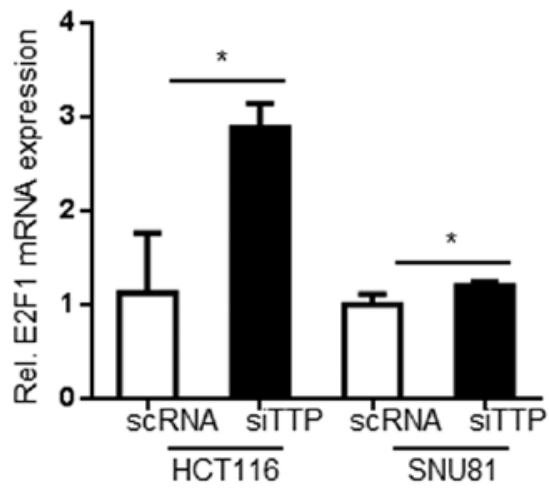

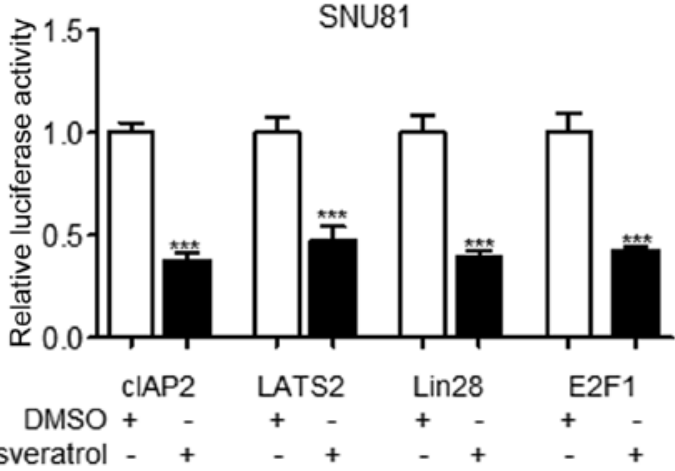

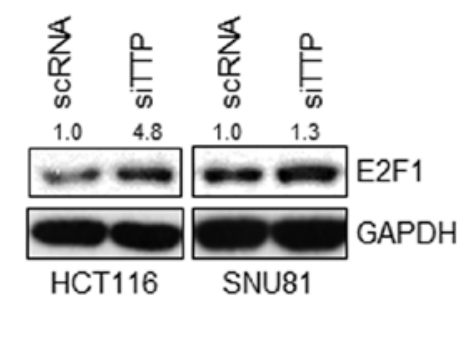

Figure 5. RSV controls the downstream target genes of TTP. (A) HCT116 and SNU81 cells were transfected with pGL3/TTPp-1411 containing the TTP promoter $(-1343$ to +68$)$ for $24 \mathrm{~h}$ and treated with RSV at increasing doses for $24 \mathrm{~h}$. Following treatment with RSV for $24 \mathrm{~h}$, the luciferase activity was measured. The expression levels obtained from pGL3-basic (empty vector)-transfected cells without treatment with RSV were set to 1. Each bar represents the mean \pm SD of three independent experiments. ${ }^{* * *} \mathrm{P}<0.001$. (B) RSV induced the mRNA-decaying activity of TTP. HCT116 and SNU81 cells were transfected with psiCHECK2-cIAP2, LATS2, Lin28 and E2F1 3'UTRs. At $24 \mathrm{~h}$ post-transfection, cells were treated with $20 \mu \mathrm{M}$ RSV for $24 \mathrm{~h}$, followed by determination of the luciferase activity. The Renilla luciferase activity was normalized to the firefly luciferase activity. The luciferase activity obtained from psiCHECK2-cIAP2, LATS2, Lin28, and E2F1 3'UTR-transfected and DMSO-treated cells was set to 1. Each bar represents the mean \pm standard deviation of three independent experiments. ${ }^{* * * *} \mathrm{P}<0.001$ vs. respective control. (C) TTP inhibits E2F1 expression in colorectal cancer cells. siTTP increased the mRNA and protein expression levels of E2F1 in HCT116 and SNU81 cells. Each bar represents the mean \pm standard deviation of three independent experiments. ${ }^{*} \mathrm{P}<0.05$ vs. respective control. TTP, tristetraprolin; RSV, resveratrol; DMSO, dimethyl sulfoxide; ns, not significant; SD, standard deviation; cIAP2, baculoviral IAP repeat containing 3; LATS2, large tumor suppressor kinase 2; Lin28, lin-28 homolog A; E2F1, E2F transcription factor 1;si, small interfering; sc, scramble.

increased TTP expression. Furthermore, RSV regulated genes associated with inflammation, cell proliferation, cell death, angiogenesis and metastasis, and suppressed Myc, KRAS, and FOS gene expression. The microarray experiment also indicated that RSV suppressed E2F1, a downstream target gene of TTP. Consistent with the microarray data, the RT-qPCR data indicated that RSV increased TTP expression in HCT116 and SNU81 cells in a dose-dependent manner. Similar results were also found with respect to the western blot analysis, wherein RSV administration dose-dependently increased TTP protein expression. Furthermore, RSV restored TTP mRNA expression following TTP silencing in HCT116 and SNU81 cells. siRNA-induced TTP inhibition attenuated the effects of RSV on cell growth. These results suggested that 
TTP may be involved in the effect of RSV on the inhibition of human colorectal cancer cell growth. RSV inhibited HCT116 and SNU81 cell proliferation by upregulating TTP. The present observations are in accordance with earlier studies wherein RSV increased TTP expression in glioma and breast cancer cells $(31,39)$. RSV was demonstrated to inhibit MCF-7 cell proliferation by upregulating TTP via COX-2 and VEGF downregulation, and inducible nitric oxide synthase upregulation (31). Furthermore, RSV increased TTP expression to induce glioma cell apoptosis in U87MG human glioma cells (39). These results suggested that RSV upregulates TTP expression in colorectal cancer cells.

Given that TTP gene silencing triggers cancer development, it may be hypothesized that the loss of TTP function in cancer cells may induce transcriptional silencing through TTP promoter regulation. The present study indicated that RSV increased the mRNA and protein expression levels of TTP in human colorectal cancer cells. Further studies regarding whether RSV regulates TTP promoter activity in colorectal cancer cells demonstrated that RSV significantly increased TTP promoter activity in HCT116 and SNU81 cells. Furthermore, RSV significantly inhibited the promoter activities of cIAP2, E2F1, LATS2 and Lin28, which are downstream target genes of TTP in HCT116 and SNU81 cells. RSV enhanced the TTP inhibitory activity in HCT116 and SNU81 cells by negatively regulating cIAP2, E2F1, LATS2 and Lin28 expression. These findings are in accordance with earlier studies wherein TTP overexpression suppressed the stability of E2F1 and Lin28 mRNA $(42,57)$, and controlled the stability of cIAP2 and LATS 2 mRNA by binding to the 3'UTR of cIAP2 mRNA or promoting let-7 biogenesis $(38,43)$, demonstrating that cIAP2, E2F1, LATS2, and Lin28 may be physiological targets of TTP. In addition, in agreement with previous studies, it was demonstrated that siTTP significantly increased the mRNA and protein expression levels of E2F1 in HCT116 and SNU81 cells. Likewise, other studies have reported that TTP inhibits the expression of LIN28, cIAP and LATS2 in human cancer cells $(40,41,43,44)$. Therefore, it may be inferred that RSV suppresses the viability of colorectal cancer cells by regulating the stability of LIN28, cIAP and LATS2 mRNA, mediated via TTP regulation. In conclusion, the results of the present study suggested RSV inhibits the proliferation and invasion/metastasis of colorectal cancer cells by upregulating TTP, which is associated with the downregulation of TTP target genes, including cIAP2, E2F1, LATS2 and Lin28.

\section{Acknowledgements}

Not applicable.

\section{Funding}

The present study was supported by the 'Research Base Construction Fund Support Program' funded by Chonbuk NationalUniversity in 2017; by grants from the MedicalResearch Center Program (grant no. NRF-2017R1A5A2015061) through the National Research Foundation, which is funded by the Korean government (MSIP); by the Basic Science Research Program (grant no. 2015R1C1A2A01054054); and by a grant from the Korea Health Technology R\&D Project through the Korea Health Industry Development Institute, funded by the Ministry of Health \& Welfare, Republic of Korea (grant no. HI16C1866).

\section{Availability of data and materials}

All data generated or analyzed during this study are included in this published article.

\section{Authors' contributions}

SRL and HJ conceived the study and drafted the manuscript. WTK and WZK performed the immunoassays and molecular studies. SZK performed the molecular studies and SHL participated in the statistical analysis and helped to draft the manuscript. SMK designed the research and drafted the manuscript. All authors read and approved the final manuscript.

\section{Ethics approval and consent to participate}

Not applicable.

\section{Consent for publication}

Not applicable.

\section{Competing interests}

The authors declare that they have no competing interests.

\section{References}

1. Arnold M, Sierra MS, Laversanne M, Soerjomataram I, Jemal A and Bray F: Global patterns and trends in colorectal cancer incidence and mortality. Gut 66: 683-691, 2017.

2. Pan R, Zhu M, Yu C, Lv J, Guo Y, Bian Z, Yang L, Chen Y, Hu Z, Chen Z, et al; China Kadoorie Biobank Collaborative Group: Cancer incidence and mortality: A cohort study in China, 2008-2013. Int J Cancer 141: 1315-1323, 2017.

3. Chen W, Zheng R, Zhang S, Zeng H, Xia C, Zuo T, Yang Z, Zou X and He J: Cancer incidence and mortality in China, 2013. Cancer Lett 401: 63-71, 2017.

4. Shin A, Jung KW and Won YJ: Colorectal cancer mortality in Hong Kong of China, Japan, South Korea, and Singapore. World J Gastroenterol 19: 979-983, 2013.

5. Fitzgerald TL, Biswas T, O'Brien K, Zervos EE and Wong JH: Neoadjuvant radiotherapy for rectal cancer: Adherence to evidencebased guidelines in clinical practice. World J Surg 37: 639-645, 2013.

6. Murray DM, Katz ML, Post DM, Pennell ML, Young GS, Tatum CM and Paskett ED: Enhancing cancer screening in primary care: Rationale, design, analysis plan, and recruitment results. Contemp Clin Trials 34: 356-363, 2013.

7. Halabi WJ, Kang CY, Jafari MD, Nguyen VQ, Carmichael JC, Mills S, Stamos MJ and Pigazzi A: Robotic-assisted colorectal surgery in the United States: A nationwide analysis of trends and outcomes. World J Surg 37: 2782-2790, 2013.

8. Lu YW and Wang KH: Research progress on genetic heterogeneity between primary and paired metastatic colorectal cancer. Yi Chuan 39: 482-490, 2017.

9. Kopetz S, Chang GJ, Overman MJ, Eng C, Sargent DJ,Larson DW, Grothey A, Vauthey JN, Nagorney DM and McWilliams RR: Improved survival in metastatic colorectal cancer is associated with adoption of hepatic resection and improved chemotherapy. J Clin Oncol 27: 3677-3683, 2009.

10. Loree JM and Kopetz S: Recent developments in the treatment of metastatic colorectal cancer. Ther Adv Med Oncol 9: 551-564, 2017.

11. Midgley RS, Yanagisawa Y and Kerr DJ: Evolution of nonsurgical therapy for colorectal cancer. Nat Clin Pract Gastroenterol Hepatol 6: 108-120, 2009. 
12. McCubrey JA, Lertpiriyapong K, Steelman LS, Abrams SL, Yang LV, Murata RM, Rosalen PL, Scalisi A, Neri LM, Cocco L, et al: Effects of resveratrol, curcumin, berberine and other nutraceuticals on aging, cancer development, cancer stem cells and microRNAs. Aging (Albany NY) 9: 1477-1536, 2017.

13. de Lima E Silva TC, da Silveira LTR, Fragoso MF, da Silva FRM, Martinez MF, Zapaterini JR, Diniz OHG, Scarano WR and Barbisan LF: Maternal resveratrol treatment reduces the risk of mammary carcinogenesis in female offspring prenatally exposure to 2,3,7,8-tetrachlorodibenzo-p-dioxin. Horm Cancer 8: 286-297, 2017

14. Perez-Vizcaino F and Fraga CG: Research trends in flavonoids and health. Arch Biochem Biophys 646: 107-112, 2018.

15. Darwish MA, Abo-Youssef AM, Khalaf MM, Abo-Saif AA, Saleh IG and Abdelghany TM: Resveratrol influences platinum pharmacokinetics: A novel mechanism in protection against cisplatin-induced nephrotoxicity. Toxicol Lett 290: 73-82, 2018.

16. Kiskova T,Demeckova V, JendzelovskaZ, Kiktava M, VenglovskaK, Bohmdorfer M, Jager W and Thalhammer T: Nocturnal resveratrol administration inhibits chemically induced breast cancer formation in rats. J Physiol Pharmacol 68: 867-875, 2017.

17. Guthrie AR, Chow HS and Martinez JA: Effects of resveratrol on drug- and carcinogen-metabolizing enzymes, implications for cancer prevention. Pharmacol Res Perspect 5: e00294, 2017.

18. Bartolacci C, Andreani C, Amici A and Marchini C: Walking a tightrope: A perspective of resveratrol effects on breast cancer. Curr Protein Pept Sci 19: 311-322, 2018.

19. Rauf A, Imran M, Butt MS, Nadeem M, Peters DG and Mubarak MS: Resveratrol as an anti-cancer agent: A review. Crit Rev Food Sci Nutr 58: 1428-1447, 2018

20. Feng Y, Zhou J and Jiang Y: Resveratrol in lung cancer- a systematic review. J BUON 21: 950-953, 2016.

21. Yin TF, Wang M, Qing Y, Lin YM and Wu D: Research progress on chemopreventive effects of phytochemicals on colorectal cancer and their mechanisms. World J Gastroenterol 22: 7058-7068, 2016.

22. Li C, Xu X, Tao Z, Sun C and Pan Y: Resveratrol derivatives: An updated patent review (2012-2015). Expert Opin Ther Pat: $1-12,2016$.

23. Li YH, Niu YB, Sun Y, Zhang F, Liu CX, Fan L and Mei QB Role of phytochemicals in colorectal cancer prevention. World $\mathrm{J}$ Gastroenterol 21: 9262-9272, 2015.

24. Fajardo AM and Piazza GA: Chemoprevention in gastrointestinal physiology and disease. Anti-inflammatory approaches for colorectal cancer chemoprevention. Am J Physiol Gastrointest Liver Physiol 309: G59-G70, 2015.

25. Carter LG, D'Orazio JA and Pearson KJ: Resveratrol and cancer: Focus on in vivo evidence. Endocr Relat Cancer 21: R209-R225, 2014.

26. Juan ME, Alfaras I and Planas JM: Colorectal cancer chemoprevention by trans-resveratrol. Pharmacol Res 65: 584-591, 2012

27. Gong WH, Zhao N, Zhang ZM, Zhang YX, Yan L and Li JB: The inhibitory effect of resveratrol on COX-2 expression in human colorectal cancer: A promising therapeutic strategy. Eur Rev Med Pharmacol Sci 21: 1136-1143, 2017.

28. Karimi Dermani F, Saidijam M, Amini R, Mahdavinezhad A, Heydari K and Najafi R: Resveratrol inhibits proliferation, invasion, and epithelial-mesenchymal transition by increasing miR-200c expression in HCT-116 colorectal cancer cells. J Cell Biochem 118: 1547-1555, 2017.

29. Buhrmann C, Shayan P, Popper B, Goel A and Shakibaei M: Sirtl is required for resveratrol-mediated chemopreventive effects in colorectal cancer cells. Nutrients 8: 145, 2016.

30. Baou M, Jewell A and Murphy JJ: TIS11 family proteins and their roles in posttranscriptional gene regulation. J Biomed Biotechnol 2009: 634520, 2009

31. Li C, Tang C and He G: Tristetraprolin: A novel mediator of the anticancer properties of resveratrol. Genet Mol Res 15: 15, 2016

32. Deng K, Wang H, Shan T, Chen Y, Zhou H, Zhao Q and Xia J: Tristetraprolin inhibits gastric cancer progression through suppression of IL-33. Sci Rep 6: 24505, 2016.

33. Pandiri I, Chen Y, Joe Y, Kim HJ, Park J, Chung HT and Park JW: Tristetraprolin mediates the anti-proliferative effects of metformin in breast cancer cells. Breast Cancer Res Treat 156: 57-64, 2016.

34. Wei ZR, Liang C, Feng D, Cheng YJ, Wang WM, Yang DJ, Wang YX and Cai QP: Low tristetraprolin expression promotes cell proliferation and predicts poor patients outcome in pancreatic cancer. Oncotarget 7: 17737-17750, 2016.

35. Xu L, Ning H, Gu L, Wang Q, Lu W, Peng H, Cui W, Ying B, Ross CR, Wilson GM, et al: Tristetraprolin induces cell cycle arrest in breast tumor cells through targeting AP-1/c-Jun and NF- $\kappa B$ pathway. Oncotarget 6: 41679-41691, 2015.
36. Sobolewski C, Sanduja S, Blanco FF, Hu L and Dixon DA Histone deacetylase inhibitors activate tristetraprolin expression through induction of early growth response protein 1 (EGR1) in colorectal cancer cells. Biomolecules 5: 2035-2055, 2015.

37. Kang S, Min A, Im SA, Song SH, Kim SG, Kim HA, Kim HJ, Oh DY, Jong HS, Kim TY, et al: TGF- $\beta$ suppresses COX-2 expression by tristetraprolin-mediated RNA destabilization in A549 human lung cancer cells. Cancer Res Treat 47: 101-109, 2015.

38. Lee HH, Son YJ, Lee WH, Park YW, Chae SW, Cho WJ, Kim YM, Choi HJ, Choi DH, Jung SW, et al: Tristetraprolin regulates expression of VEGF and tumorigenesis in human colon cancer. Int J Cancer 126: 1817-1827, 2010.

39. Ryu J, Yoon NA, Seong H, Jeong JY, Kang S, Park N, Choi J, Lee DH, Roh GS, Kim HJ, et al: Resveratrol induces glioma cell apoptosis through activation of tristetraprolin. Mol Cells 38: 991-997, 2015

40. Lee JY, Kim HJ, Yoon NA, Lee WH, Min YJ, Ko BK, Lee BJ, Lee A, Cha HJ, Cho WJ, et al: Tumor suppressor p53 plays a key role in induction of both tristetraprolin and let-7 in human cancer cells. Nucleic Acids Res 41: 5614-5625, 2013.

41. Kim CW, Kim HK, Vo MT, Lee HH, Kim HJ, Min YJ, Cho WJ and Park JW: Tristetraprolin controls the stability of cIAP2 mRNA through binding to the 3'UTR of cIAP2 mRNA. Biochem Biophys Res Commun 400: 46-52, 2010.

42. Lee HH, Lee SR and Leem SH: Tristetraprolin regulates prostate cancer cell growth through suppression of E2F1. J Microbiol Biotechnol 24: 287-294, 2014.

43. Lee HH, Vo MT, Kim HJ, Lee UH, Kim CW, Kim HK, Ko MS, Lee WH, Cha SJ, Min YJ, et al: Stability of the LATS2 tumor suppressor gene is regulated by tristetraprolin. J Biol Chem 285: 17329-17337, 2010.

44. Kim CW, Vo MT, Kim HK, Lee HH, Yoon NA, Lee BJ, Min YJ, Joo WD, Cha HJ, Park JW, et al: Ectopic over-expression of tristetraprolin in human cancer cells promotes biogenesis of let-7 by down-regulation of Lin28. Nucleic Acids Res 40: 3856-3869, 2012

45. Li W, Matsuoka M, Kai M, Thapa P, Khadge S, Hagge DA, Brennan PJ and Vissa V: Real-time PCR and high-resolution melt analysis for rapid detection of Mycobacterium leprae drug resistance mutations and strain types. J Clin Microbiol 50: 742-753, 2012.

46. Ashrafi R, Bruneaux M, Sundberg LR, Pulkkinen K and Ketola T: Application of high resolution melting assay (HRM) to study temperature-dependent intraspecific competition in a pathogenic bacterium. Sci Rep 7: 980, 2017.

47. Du Z, Zhou F, Jia Z, Zheng B, Han S, Cheng J, Zhu G and Huang P: The hedgehog/Gli-1 signaling pathways is involved in the inhibitory effect of resveratrol on human colorectal cancer HCT116 cells. Iran J Basic Med Sci 19: 1171-1176, 2016.

48. Feng M,Zhong LX, Zhan ZY, Huang ZH and Xiong JP: Resveratrol treatment inhibits proliferation of and induces apoptosis in human colon cancer cells. Med Sci Monit 22: 1101-1108, 2016.

49. Ali I and Braun DP: Resveratrol enhances mitomycin C-mediated suppression of human colorectal cancer cell proliferation by upregulation of p21WAF1/CIP1. Anticancer Res 34: 5439-5446, 2014.

50. Liu B, Zhou Z, Zhou W, Liu J, Zhang Q, Xia J, Liu J, Chen N, $\mathrm{Li} \mathrm{M}$ and Zhu R: Resveratrol inhibits proliferation in human colorectal carcinoma cells by inducing G1/S-phase cell cycle arrest and apoptosis through caspase/cyclin-CDK pathways. Mol Med Rep 10: 1697-1702, 2014.

51. Guo J, Qu H, Chen Y and Xia J: The role of RNA-binding protein tristetraprolin in cancer and immunity. Med Oncol 34: 196, 2017.

52. Guo J, Wang H, Jiang S, Xia J and Jin S: The Cross-talk between tristetraprolin and cytokines in cancer. Anticancer Agents Med Chem 17: 1477-1486, 2017.

53. Wang Q, Ning H, Peng H, Wei L, Hou R, Hoft DF and Liu J: Tristetraprolin inhibits macrophage IL-27-induced activation of antitumour cytotoxic T cell responses. Nat Commun 8: 867, 2017.

54. Vo MT, Choi SH, Lee JH, Hong CH, Kim JS, Lee UH, Chung HM, Lee BJ, Park JW and Cho WJ: Tristetraprolin inhibits mitochondrial function through suppression of $\alpha$-Synuclein expression in cancer cells. Oncotarget 8: 41903-41920, 2017.

55. Zeng B, Zhu D, Su Z, Li Z and Yu Z: Tristetraprolin exerts tumor suppressive functions on the tumorigenesis of glioma by targeting IL-13. Int Immunopharmacol 39: 63-70, 2016.

56. Lee HH, Yang SS, Vo MT, Cho WJ, Lee BJ, Leem SH, Lee SH, Cha HJ and Park JW: Tristetraprolin down-regulates IL-23 expression in colon cancer cells. Mol Cells 36: 571-576, 2013.

57. Cha HJ, Lee HH, Chae SW, Cho WJ, Kim YM, Choi HJ, Choi DH, Jung SW, Min YJ, Lee BJ, et al: Tristetraprolin downregulates the expression of both VEGF and COX-2 in human colon cancer. Hepatogastroenterology 58: 790-795, 2011. 